\title{
ANALISIS GETARAN PELEDAKAN TERHADAP PABRIK PENGOLAHAN EMAS PT. AGINCOURT RESOURCES, TAPANULI SELATAN, SUMATERA UTARA
}

\author{
Pantjanita N Hartami ${ }^{(1)}$, Taat T Purwiyono ${ }^{(1)}$, Handoyo $\mathbf{M}^{(2)}$, Rudolf ${ }^{(3)}$, Yuga $\mathbf{M}^{(1)}$, \\ I Gusti Bagus ${ }^{(1)}$
}

(1) Mining Engineering Department, Trisakti University, Jakarta

(2) Indonesian Blasting Engineer Society

(3) PT Agincourt Resources

\begin{abstract}
ABSTRAK
Getaran tanah merupakan salah satu efek peledakan yang harus diperhatikan terutama pada saat aktivitas penambangan berada di dekat bangunan penting dan masyarakat. Penambangan emas PT. Agincourt Resources di Tapanuli Selatan, Sumatera Utara, Indonesia melakukan operasi penambangan di 2 pit yaitu pit Purnama dan pit Barani. Posisi pit Purnama berdekatan dengan processing plant yang digunakan sebagai tempat peleburan dan pemurnian emas dengan jarak sekitar $\pm 30 \mathrm{~m}$, sedangkan Pit Barani yang berjarak sekitar 1200 meter dari perumahan penduduk. Paper ini difokuskan pada penelitian untuk mengantisipasi pengaruh getaran peledakan di pit Purnama terhadap processing plant. Penelitian dilakukan dengan mengukur getaran hasil peledakan menggunakan dua alat ukur Blasmate dan Micromate yang diletakkan di depan freeface dan di belakang freeface. Pengukuran ini bertujuan memprediksi bahan peledak per delay agar getaran hasil peledakan tidak berpengaruh terhadap bangunan. Analisis dilakukan dengan menggunakan persamaan scale distance dan software Shotplus sehingga dapat ditentukan prediksi jumlah bahan peledak per delay di setiap jarak. Dengan mengacu standar perusahaan, dan SNI 7570:2010maka akan dilakukan standarisasi jumlah bahan peledak per delay yang diijinkan
\end{abstract}

Kata Kunci: getaran peledakan, pabrik pengolahan, scaled distance, shotplus, Standar Nasional Indonesia

\begin{abstract}
Ground vibration is blasting effect that must be considered especially when mining activities are located near important buildings and communities. The activities of gold mining of PT. Agincourt Resources in Tapanuli Selatan, North Sumatra, Indonesia conducts mining operations in two pits, namely Purnama Pit and Barani Pit. Purnama Pit which is adjacent to a processing plant which is used as a gold smelting and refining with a distance of about $\pm 30 \mathrm{~m}$, and Barani Pit which is about 1200 meters from village. This paper focused to anticipate damage to the processing plant. The ground vibration measurements were carried out using 2 measuring instruments that placed in front of the freeface and behind the freeface. This measurement aims to predict charged per delay on each distance so that the ground vibration have no effect on the processing plant. The analysis was carried out by using the scaled distance and Shotplus software. Based on the analysis and referred to Indonesian National Standard for ground vibration, then charge per delay was determined
\end{abstract}

Keyword : ground vibration, processing plant, scaled distance, shotplus, Indonesian National Standard 


\section{A. PENDAHULUAN}

Kegiatan peledakan yang dilakukan pada area yang dekat dengan perumahan penduduk dan infrastruktur penting menuntut perhatian lebih dalam menangani dampak hasil peledakannya seperti airblast, flyrock, ground vibration dan fumes. Hal ini dilakukan untuk mencegah timbulnya permasalahan baik antara perusahaan dan masyarakat maupun masalah infrastruktur .

Aktivitas penambangan PT Agincourt Resources terletak di desa Aek Pining, Kecamatan Batangtoru, Kabupaten Tapanuli Selatan, Provinsi Sumatera Utara dengan pabrik pengolahan emasnya berada pada jarak sekitar 30 meter dari final wall Pit Purnama yang masih aktif (Gambar 1). Hal ini menjadi pertimbangan saat melakukan peledakan di Pit Purnama karena dikhawatirkan getaran yang dihasilkan dapat merusak infrastruktur pabrik pengolahan tersebut yang pada akhirnya dapat mengganggu proses pengolahan dan pemurnian emas.

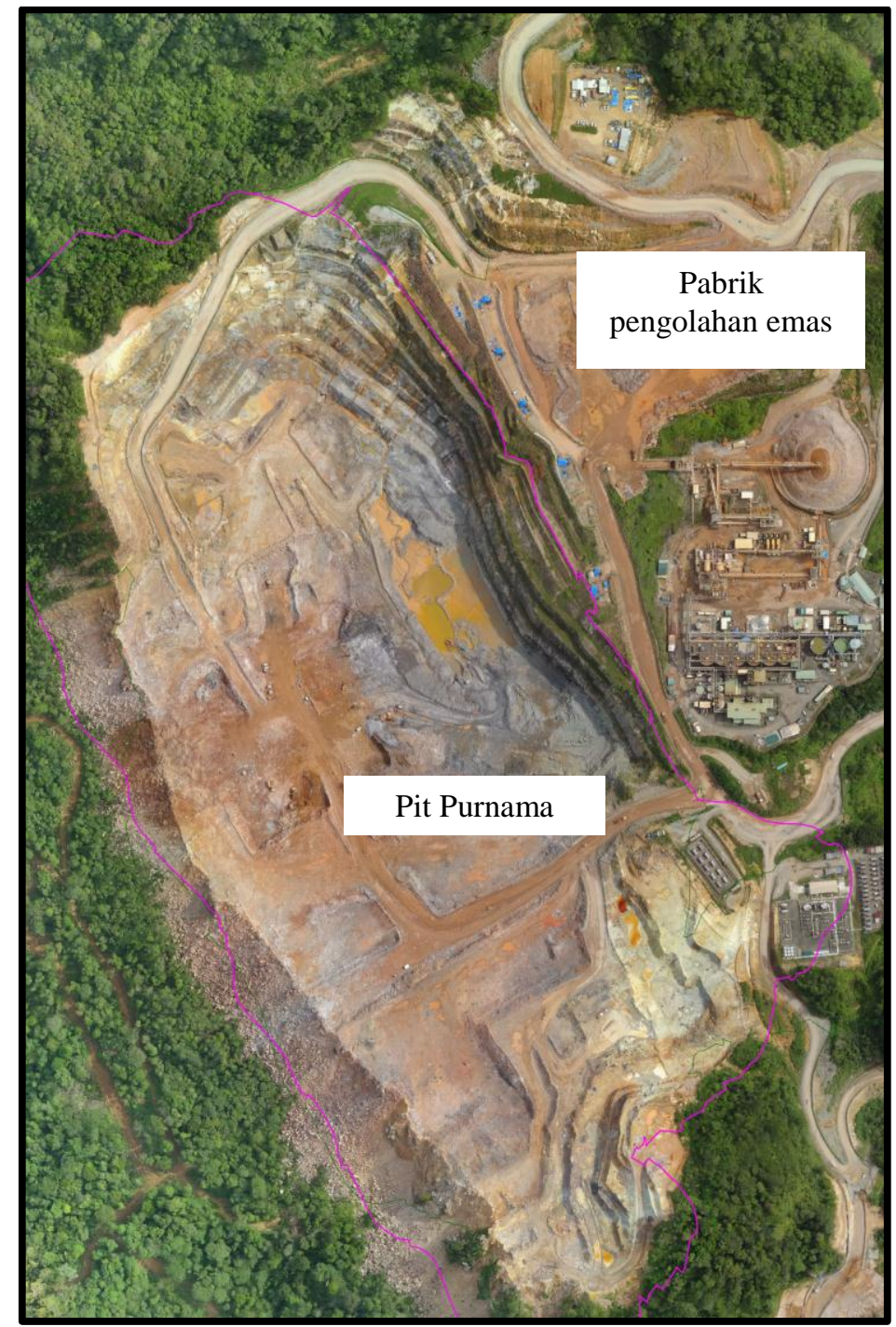

Gambar 1. Lokasi Pit Purnama dan Pabrik Pengolahan Emas

Upaya yang telah dilakukan oleh PT. Agincourt adalah dengan menggunakan Scale Depth of Burial sesuai dengan geometri peledakan sehingga penggunaan bahan peledak dapat dikontrol. Beberapa upaya lainnya adalah dengan memperpanjang waktu surface delay, tetapi fragmentasi yang dihasilkan tidak sesuai seperti yang diharapkan sehingga surface delay yang lebih kecil tetap 
digunakan. Untuk itu maka perlu dilakukan penelitian untuk mengetahui apakah jumlah bahan peledak/delay yang digunakan menghasilkan getaran yang sesuai dengan standar getaran yang berlaku, yaitu SNI 7571:2010 tentang baku tingkat getaran pada tambang terbuka dan tidak merusak infrastruktur pengolahan

\section{B. METODOLOGI PENELITIAN}

Pengukuran getaran di lapangan dilakukan dengan menggunakan Micromate 2 buah, dan Blastmate III. Data yang akan dibahas dalam paper ini merupakan data dari Blastmate III yang pada saat pengukuran diletakkan pada 2 lokasi yang berbeda, yaitu di depan dan di belakang bidang bebas. Gambar 2. menunjukkan skema pengukuran di belakang bidang bebas dan di depan bidang bebas

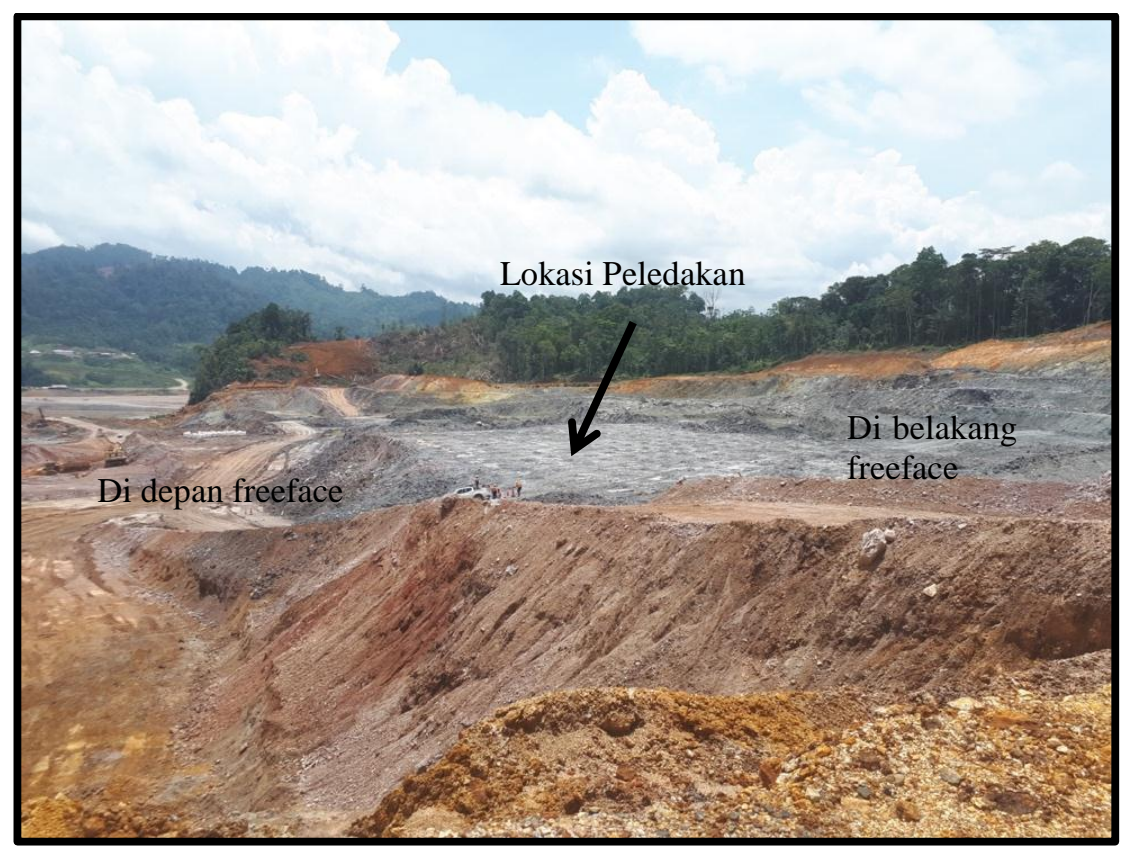

Gambar 2. Skema pengukuran getaran di depan dan belakang bidang bebas

Data jumlah bahan peledakan setiap peledakan yang dilakukan merupakan gabungan data primer yang diambil langsung di lapangan serta data sekunder yang diperoleh dalam bentuk Drill \& Blast Plan. Maximum Instantneous Charge (MIC) dapat ditentukan dari jumlah lubang yang meledak bersamaan dengan charge/lubang. Banyak lubang yang meledak bersamaan serta data charge/hole merupakan data sekunder Setelah mengetahui charge/hole dan lubang yang meledak bersamaan dapat mengetahui charge/delay pada setiap peledakan yang getarannya telah direkam.

\section{HASIL DAN PEMBAHASAN}

\section{C.1. Geometri Peledakan Aktual}

Saat ini peledakan di PT. Agincourt Resources menggunakan lubang tembak dengan diameter 127 $\mathrm{mm}$ dan pola pemboran Staggered pattern. Primer yang digunakan adalah Dayaprim $400 \mathrm{gr}$, in hole delay $500 \mathrm{~ms}$, dengan jumlah surface delay yang digunakan ada dua jenis yaitu $17 \mathrm{~ms}$, dan $25 \mathrm{~ms}$. Secara garis besar geometri peledakan yang digunakan di lokasi penelitian adalah seperti yang terlihat pada Tabel 1. 
Jumlah bahan peledak yang meledak bersamaan menyesuaikan dengan kedalaman lubang, serta diameter lubang. Pada tambang emas PT. AR variabel yang biasanya berubah adalah kedalaman lubang. Kedalaman lubang yang biasa digunakan sebesar $10 \mathrm{~m}$ atau $5 \mathrm{~m}$ dengan subdrill rata-rata 1 m. Tabel 2 menunjukkan jumlah bahan peledak yang digunakan pada setiap peledakan. Data ini merupakan data yang diambil selama bulan April 2018

Tabel 1 Geometri peledakan Aktual

\begin{tabular}{ccc}
\hline NO. & Keterangan & Besar \\
\hline 1 & Diameter lubang $(\mathrm{mm})$ & 127 \\
2 & Kedalaman lubang $(\mathrm{m})$ & 10,5 \\
3 & Subdrill $(\mathrm{m})$ & 1 \\
4 & Spacing $(\mathrm{m})$ & 3,8 \\
5 & Burden $(\mathrm{m})$ & 3,3 \\
6 & Jenis Peledakan & Nonel \\
7 & Stemming $(\mathrm{m})$ & 2,8 \\
8 & Powder Factor $(\mathrm{kg} / \mathrm{bcm})$ & 0,89 \\
9 & Surface Delay $(\mathrm{ms})$ & 17,25 \\
\hline
\end{tabular}

Tabel 2 Jumlah bahan peledak yang digunakan pada tiap peledakan

\begin{tabular}{ccccc}
\hline Tanggal & Lokasi Peledakan & $\begin{array}{c}\text { Charge/Hole } \\
(\mathrm{kg})\end{array}$ & Overlap Holes & $\begin{array}{c}\text { Charge/Delay } \\
(\mathrm{kg})\end{array}$ \\
\hline 07/04/2018 & Purnama 365-360RL & 51,6 & 5 & 258 \\
09/04/2018 & Purnama 385-380RL & 41,3 & 8 & 330,4 \\
$12 / 04 / 2018$ & Purnama 360-350RL & 109,3 & 9 & 983,7 \\
$17 / 04 / 2018$ & Purnama 385-380RL & 40,7 & 10 & 407 \\
$21 / 04 / 2018$ & Purnama 360-350RL & 107,7 & 10 & 1077 \\
$23 / 04 / 2018$ & Purnama 360-350RL & 107,4 & 5 & 537 \\
$26 / 04 / 2018$ & Purnama 360-350RL & 94,5 & 10 & 945 \\
$28 / 04 / 2018$ & Purnama 350-340RL & 98,6 & 5 & 493 \\
\hline
\end{tabular}

( Note : Time Windows $8 \mathrm{~ms}$ )

\section{C.2. Data Getaran Peledakan (Ground Vibration)}

Pengukuran nilai getaran tanah akibat peledakan dilakukan dengan posisi Blasmate III ditempatkan di depan dan di belakang freeface.

\section{C.2.1. Nilai PPV dan Frekuensi Aktual}

Pengukuran yang dilakukan merupakan gabungan dari alat ukur 1 buah Blastmate III dan 2 buah Micromate. Hasil pengukuran nilai getaran secara aktual dapat dilihat pada Tabel 3. Getaran yang dihasilkan merupakan hasil dari rambatan gelombang, sehingga setiap getaran memiliki frekuensi gelombang getaran tersebut. Frekuensi ini menunjukkan seberapa cepat getaran membentuk satu gelombang dengan satuan $(\mathrm{Hz})$. 
Tabel 3. Nilai getaran tanah hasil pengukuran aktual

\begin{tabular}{|c|c|c|c|c|c|c|c|}
\hline \multirow[b]{2}{*}{ Tanggal } & \multirow[b]{2}{*}{ Alat } & \multicolumn{3}{|c|}{ Di depan freeface } & \multicolumn{3}{|c|}{ Di belakang freeface } \\
\hline & & $\begin{array}{c}\text { Jarak } \\
(\mathrm{m})\end{array}$ & $\begin{array}{l}\text { Charge/delay } \\
(\mathrm{kg})\end{array}$ & $\begin{array}{c}\text { PPV } \\
(\mathrm{mm} / \mathrm{s})\end{array}$ & $\begin{array}{c}\text { Jarak } \\
(\mathrm{m})\end{array}$ & $\begin{array}{l}\text { Charge/delay } \\
(\mathrm{kg})\end{array}$ & $\begin{array}{l}\mathrm{PPV} \\
(\mathrm{mm} / \mathrm{s})\end{array}$ \\
\hline \multirow{3}{*}{ 07-Apr-18 } & $\mathrm{BM}$ & & & & 380 & 258 & 4,08 \\
\hline & M1 & & & & 350 & 258 & 4,51 \\
\hline & M2 & & & & 236 & 258 & 8,73 \\
\hline \multirow{2}{*}{ 09-Apr-18 } & $\mathrm{BM}$ & & & & 70 & 330,4 & 45,13 \\
\hline & M1 & 497 & 330,4 & 1,19 & & & \\
\hline \multirow{3}{*}{ 12-Apr-18 } & $\mathrm{BM}$ & 498 & 983,7 & 1,70 & & & \\
\hline & M1 & & & & 256 & 983,7 & 4,43 \\
\hline & M2 & 366 & 983,7 & 1,88 & & & \\
\hline \multirow{3}{*}{ 17-Apr-18 } & $\mathrm{BM}$ & 556 & 407 & 0,35 & & & \\
\hline & M1 & 538 & 407 & 1,22 & & & \\
\hline & M2 & & & & 104 & 407 & 48,35 \\
\hline \multirow{3}{*}{ 21-Apr-18 } & $\mathrm{BM}$ & 572 & 1077 & 1,00 & & & \\
\hline & M1 & & & & 317 & 1077 & 9,82 \\
\hline & M2 & 334 & 1077 & 6,19 & & & \\
\hline \multirow{3}{*}{ 23-Apr-18 } & $\mathrm{BM}$ & & & & 524 & 537 & 1,30 \\
\hline & M1 & & & & 319 & 537 & 3,15 \\
\hline & M2 & 334 & 537 & 2,28 & & & \\
\hline \multirow{2}{*}{ 26-Apr-18 } & $\mathrm{BM}$ & 467 & 945 & 1,83 & & & \\
\hline & M1 & 450 & 945 & 1,88 & & & \\
\hline \multirow{3}{*}{ 28-Apr-18 } & $\mathrm{BM}$ & & & & 505 & 493 & 1,03 \\
\hline & M1 & 111 & 493 & 5,82 & & & \\
\hline & M2 & & & & 113 & 493 & 5,88 \\
\hline
\end{tabular}

\section{C.2.2. Penentuan Nilai K dan M}

Untuk menentukan nilai $\mathrm{K}$ dan $\mathrm{m}$ dilakukan analisis regresi power. Nilai $\mathrm{K}$ dan $\mathrm{m}$ dalam analisis ini dipengaruhi oleh jarak, dan jumlah bahan peledak per delay. Penentuan nilai K dan $\mathrm{m}$ dengan cara mencari hubungan terhadap scale distance dan peak particle velocity. Nilai Square root scaled distance diperoleh dengan melakukan perhitungan yang menggunakan jumlah charge/delay dan jarak pengukuran

Sebagai contoh perhitungan square root scale distance pada peledakan 7 April 2018 :

$S D=\frac{380}{258^{1 / 2}}=23,67 \frac{\mathrm{m}}{\mathrm{kg}^{1 / 2}}$

Pada Tabel IV.6 menunjukkan pengelompokkan lokasi pengukuran getaran pada tiap pengukuran dilakukan untuk ketiga alat yang digunakan.

Penentuan lokasi alat dilakukan secara acak dan sesuai dengan lokasi pengukuran yang bukan merupakan timbunan serta daerah yang relatif datar agar meletakkan geophone lebih sempurna. Jarak bervariasi merupakan salah satu alasan untuk lokasi peletakan alat Blastmate III. Hal ini dilakukan agar saat penentuan scaled distance jarak dapat menunjukkan bahwa dengan berubahnya jarak maka getaran yang dihasilkan juga berubah dan agar lebih merepresentasikan rumus scaled distance yaitu dengan berubahnya jarak dan jumlah bahan peledak maka getaran akan berubah. Nilai scale distance dihubungkan dengan peak particle velocity aktual untuk mencari garis regresi. 
Pengolahan data dibagi menjadi 2 kelompok data sesuai lokasi pengukurannya yaitu di belakang freeface dan pengukuran di depan freeface. Hal ini dilakukan untuk membuktikan apakah terdapat perbedaan saat pengukuran di depan bidang bebas dan di belakangnya. Penentuan persamaan PPV yang menunjukkan nilai $\mathrm{K}$ dan $\mathrm{m}$ dapat dilakukan dengan cara menggunakan analisis regresi power. Untuk pengukuran di belakang freeface dilakukan analisis regresi power dengan hasil seperti terlihat pada Gambar 1.

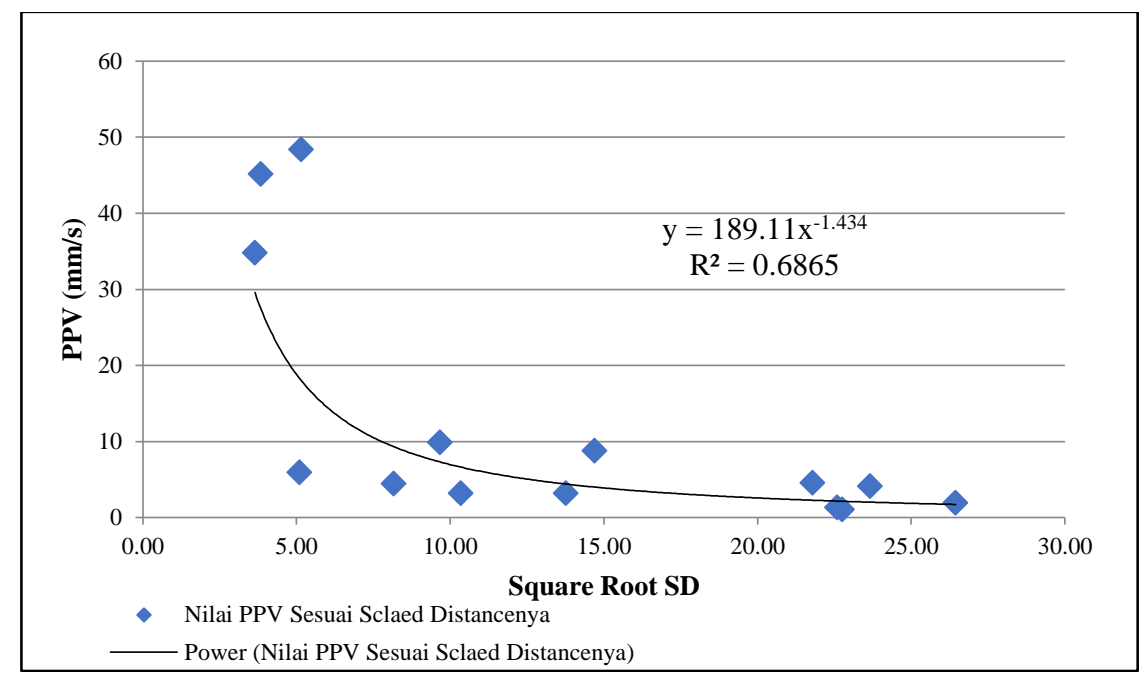

Gambar 1. Grafik PPV terhadap SRSD hasil perhitungan pengukuran getaran di belakang freeface

Pada Gambar 1 dijelaskan bahwa K dan m yang didapat dari persamaan PPV hasil analisis regresi power adalah sebesar 189,11 dan nilai $\mathrm{m}$ adalah $-1,434$. Untuk persamaan PPV yang terdapat nilai $\mathrm{K}$ dan $\mathrm{m}$ pengukuran di depan freeface yang dihitung dengan analisis regresi power dapat dilihat hasil analisisnya pada Gambar IV.6.

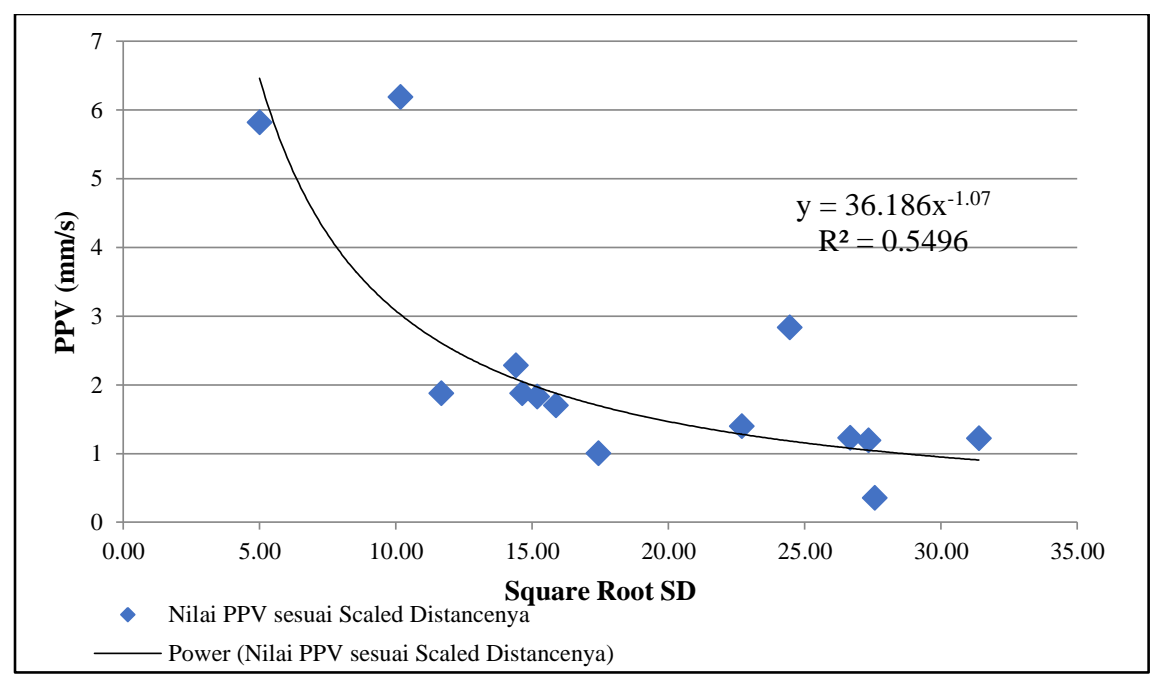

Gambar 2. Grafik PPV terhadap SRSD hasil perhitungan pengukuran getaran di depan freeface Pada Gambar 2 nilai $\mathrm{K}$ dan $\mathrm{m}$ yang didapat adalah sebesar 36,186 untuk nilai K, sedangkan untuk nilai $\mathrm{m}$ adalah sebesar $-1,07$. Hasil persamaan diatas akan digunakan kembali untuk menentukan PPV prediksi sesuai dari lokasinya getaran tersebut di ukur. Berikut ini adalah persamaan yang dihasilkan dari analisis regresi power :

1. Persamaan prediksi getaran tanah di belakang freeface :

$$
P P V=189,11 .(S D)^{-1,434}
$$

2. Persamaan prediksi getaran tanah di depan freeface : 


$$
P P V=36,186 \cdot(S D)^{-1,07}
$$

\section{C.2.3. Prediksi Getaran Peledakan dengan Persamaan PPV}

Dengan menggunakan persamaan PPV yang dihasilkan dari pengukuran getaran di atas, maka dapat ditentukan prediksi bahan peledak yang meledak bersamaan. Prediksi ini dilakukan dengan tujuan memenuhi Standar Nasional Indonesia (SNI) 7571:2010 serta berguna untuk mendapatkan gambaran tentang besarnya PPV yang mungkin dihasilkan, sehingga dapat menjadi acuan untuk melakukan peledakan lainnya. Karena lubang ledak memiliki kedalaman yang bervariasi yaitu 5 meter dan 10 meter, maka jumlah isian per lubang bisa berbeda. Prediksi dilakukan dengan menggunakan variasi berat bahan peledak $200 \mathrm{~kg}$ hingga maksimal nilai $1000 \mathrm{~kg}$ serta variasi jarak mulai $50 \mathrm{~m}$ hingga $1000 \mathrm{~m}$. Rumus yang digunakan dalam memprediksi getaran adalah persamaan yang dihasilkan pada analisis software blastware.

Untuk prediksi getaran di belakang freeface dapat dilihat pada Gambar 3, sedangkan untuk di depan freeface dapat dilihat pada Gambar 4. Dari prediksi getaran baik di belakang maupun di depan freeface menghasilkan beberapa pilihan jumlah chargeldelay. Hal ini dilakukan karena geometri peledakan tidak selalu sama dan semakin banyak jumlah lubang membuat lubang yang meledak bersamaan semakin banyak. PT. Agincourt Resources menggunakan surface delay sebesar $17 \mathrm{~ms}$ dan $25 \mathrm{~ms}$. Hal ini menyebabkan kemungkinannya banyak lubang yang meledak bersamaan saat jumlah lubang yang diledakkan banyak. Tetapi hal ini tetap dipertahankan karena batuan di lokasi merupakan batuan yang keras, sehingga harus menggunakan delay kecil agar fragmentasi dapat tercapai dan tidak memperlambat proses pengolahan batuan.

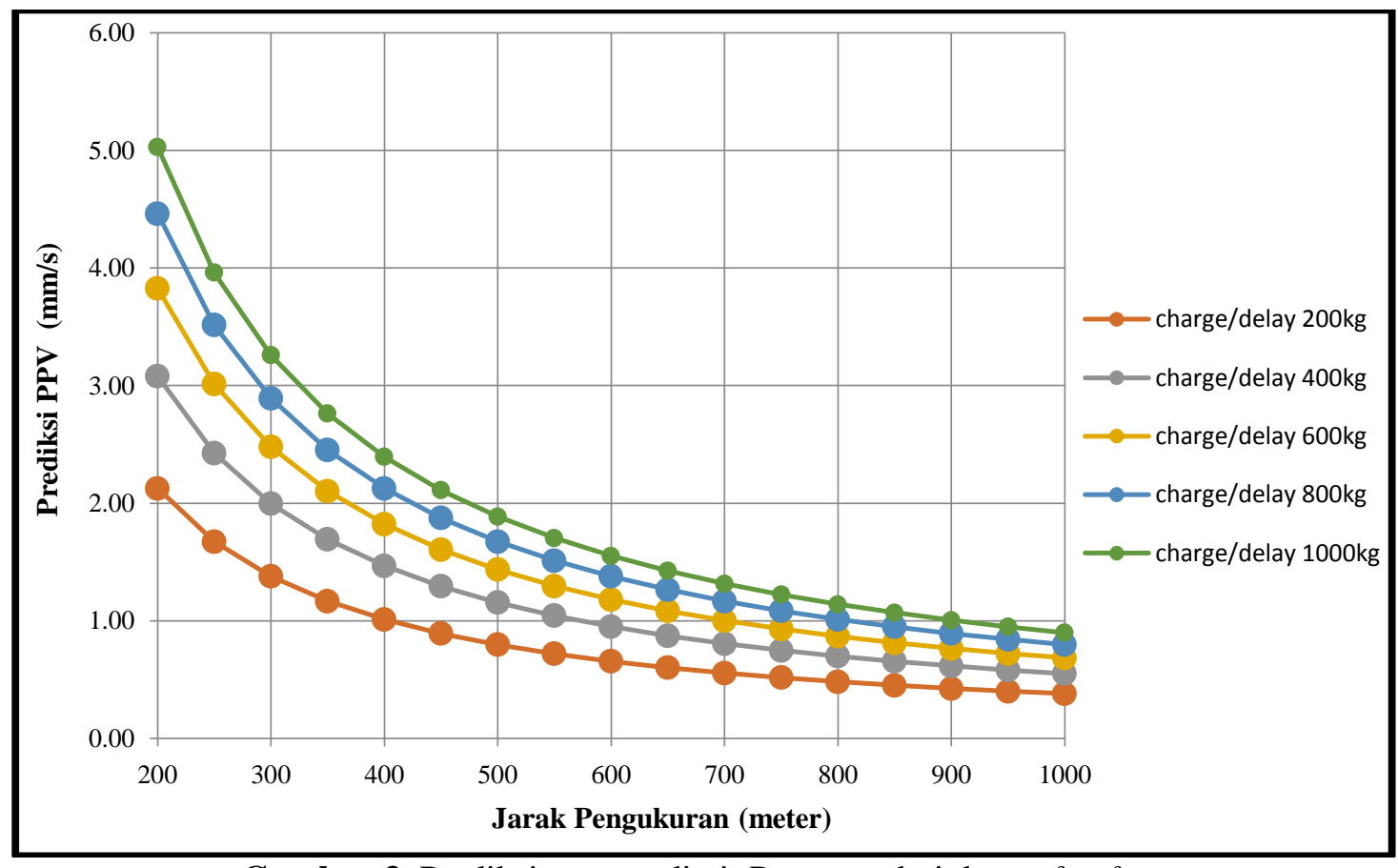

Gambar 3. Prediksi getaran di pit Purnama dari depan freeface 


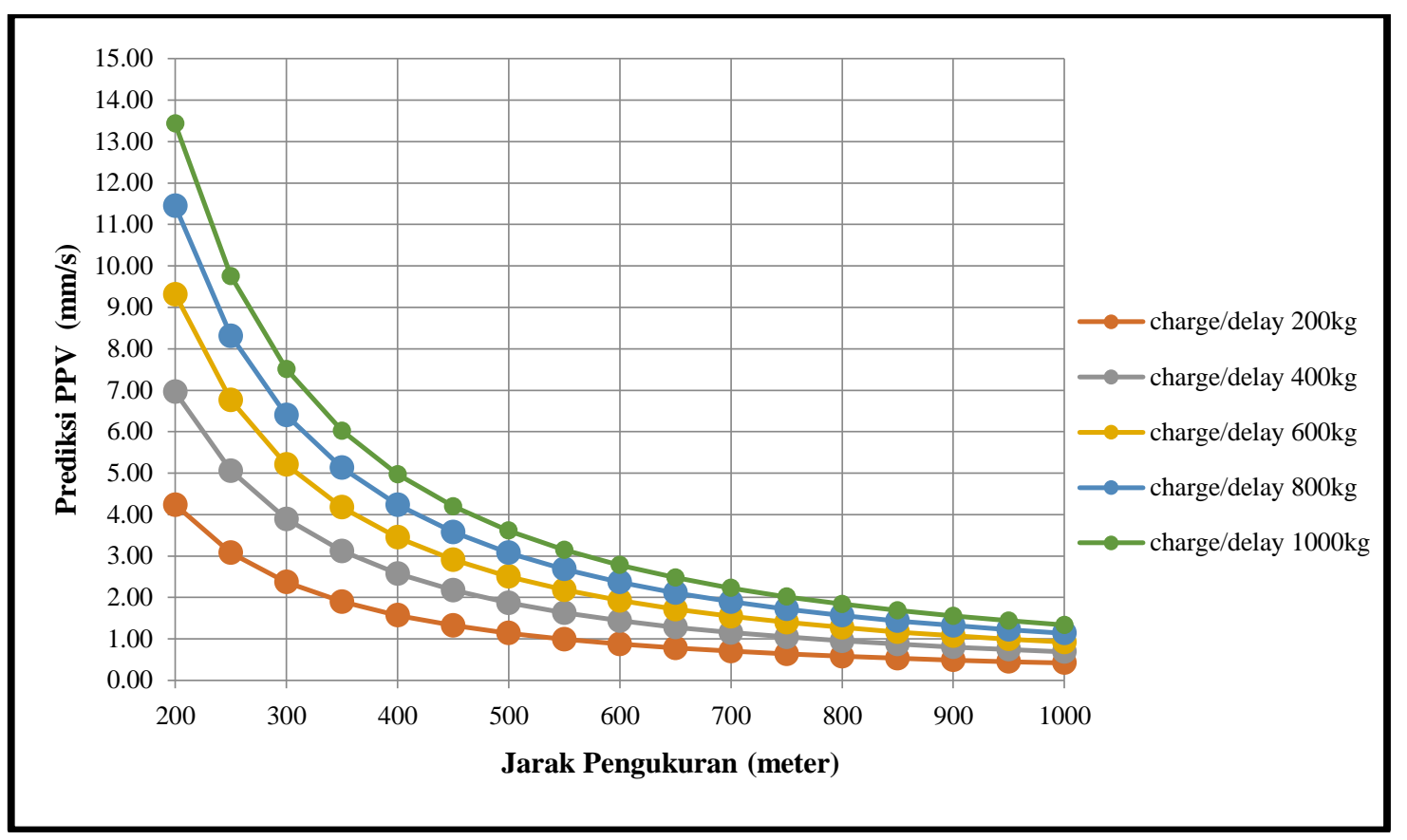

Gambar 5 Prediksi getaran di pit Purnama dari belakang freeface

Pada Gambar 4 terlihat bahwa dengan bertambahnya jarak maka nilai getaran akan semakin rendah. Getaran $3 \mathrm{~mm} / \mathrm{s}$ pada peraturan SNI 7571:2010 merupakan batas untuk bangunan dengan tipe kelas 2 yaitu bangunan dengan pondasi, pasangan bata dan adukan semen saja, termasuk bangunan dengan pondasi dari kayu dan lantainya diberi adukan semen. Berdasarkan pada grafik pada Gambar 4, pada jarak $300 \mathrm{~m}$ maka charge/delay $1000 \mathrm{~kg}$ tidak disarankan untuk meledak karena tidak memenuhi $3 \mathrm{~mm} / \mathrm{s}$, sedangkan pada jarak $500 \mathrm{~m}$ semua getaran sudah berada dibawah $3 \mathrm{~mm} / \mathrm{s}$.

Untuk prediksi getaran dari belakang freeface dapat dilihat pada Gambar 5 bahwa nilai PPV yang dihasilkan pada jarak $1000 \mathrm{~m}$ PPV sudah berada di bawah $2 \mathrm{~mm} / \mathrm{s}$. Getaran tersebut sudah cukup rendah jika terdapat bangunan historis, untuk perumahan warga jika jaraknya $600 \mathrm{~m}$ maka getaran sudah dapat dikatakan aman dan masih bisa ditangani oleh bangunan tersebut tanpa mengalami efek samping yang besar semakin besar juga charge/delay yang dapat diledakkan

\section{C.2.4. Pengaruh Getaran Menurut SNI 7571:2010 Terhadap Bangunan Pabrik Pengolahan}

Berdasarkan hasil pengukuran menggunakan Blastmate III didapatkan frekuensi rata-rata pada pengukuran area pit sebesar 2-11 Hz. Berdasarkan tingkat frekuensi area pit ini getaran yang memiliki ppv besar anak sangat berpengaruh terhadap kekuatan bangunan. Untuk memahami hubungan frekuensi dengan peak particle velocity terhadap tingkat kerusakan bangunan maka dapat dilihat pada 


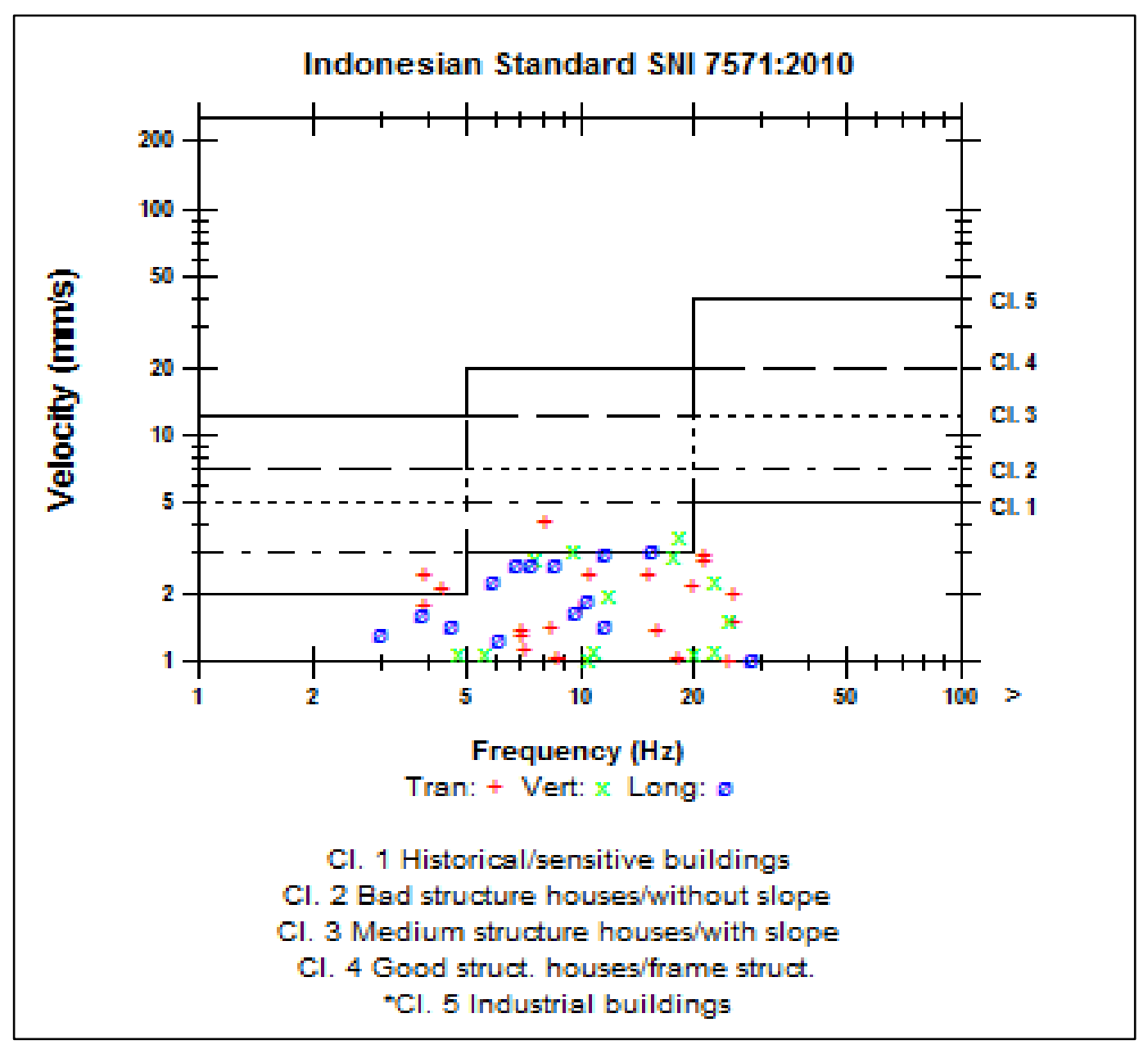

Berdasarkan hubungan tersebut bahwa semakin tinggi frekuensi akan memberi dampak yang lebih kecil terhadap setiap kelas bangunan, contohnya jika ppv 3 sudah bisa mengakibatkan kerusakan pada bangunan tipe 1 saat frekeunsi dibawah 5. Tetapi saat frekuensi getaran diatas 20 maka ppv $2 \mathrm{~mm} / \mathrm{s}$ tidak memberikan dampak pada bangunan tipe 1 tersebut.

Acuan ini yang akan dijadikan dasar jika untuk peledakan berikutnya yang dekat dengan pabrik pengolahan. Kantor yang dekat dengan pit tambang juga dapat mengalami kerusakan jika terkena getaran yang besar. Prediksi getaran di tambang Martabe ini dapat berguna jika terdapat peledakan di dekat infrastruktur sehingga dapat memperkirakan getaran yang dihasilkan sehingga dapat dilakukan pencegahan kerusakan akibat getaran yang besar. Pencegahan tersebut dilakukan dengan membuat prediksi getaran dengan rumus yang telah didapatkan, lalu jika getaran yang diprediksi melebihi dari getaran yang seharusnya telah ditetapkan maka variabel yang dapat diubah adalah jumlah bahan peledak yang meledak bersamaan karena jarak tidak dapat diubah jika merupakan infrastruktur atau objek vital.

\section{KESIMPULAN}

Berdasarkan peraturan SNI 7571:2010 batas getaran untuk pabrik pengolahan adalah $3 \mathrm{~mm} / \mathrm{s}$ ini. Dari hasil penelitian ini dapat disimpulkan bahwa untuk memenuhi getaran tersebut, pada jarak 300m maka tidak disarankan untuk menggunakan charge/delay $1000 \mathrm{~kg}$ karena tidak memenuhi 3 $\mathrm{mm} / \mathrm{s}$, sedangkan pada jarak $500 \mathrm{~m}$ semua getaran sudah berada dibawah $3 \mathrm{~mm} / \mathrm{s}$

\section{DAFTAR PUSTAKA}


Dr. David L. Hutchisuni, ME, Phd. MNZIG, Design of Multistorey Earthquake Resistant Buildings, penerbit Departemen Pekerjaan Umum, 1981.

Kiyoshimoto, Analisis Perancangan Gedung Tahan Gempa, penerbit Erlangga, Jakarta, 1990

Neil Morris, Gempa Bumi, penerbit PT. Elex Media Komputindo, 2002.

Scott,A dkk . 1996 . Open Pit Blast Design Analysis and Optimisation . Australia :The University of Queensland.

Sukanta I. N., dkk, 2010. Accelerograph BMKG dalam Penentuan Peta Intensitas Gempa Kuat. Puslibang BMKG https://www.scribd.com/document/84227253/139 